\title{
Optimal Gene Expression for Efficient Replication of Herpes Simplex Virus Type 1 (HSV-1)
}

\author{
Jun Nakabayashi \\ University of Tokyo \\ Japan
}

\section{Introduction}

Herpesviridae is a large class of animal viruses. Herpes simplex virus type 1 (HSV-1) is a prototypic virus in this taxonomic group. HSV-1 belongs to the Alphaherpesviridae which are most frequently responsible for cold-sore lesions around the lips and mouth. HSV-1 is extensively studied not only as a causative agent of human disease but also as a general model system for the gene expression. In the lytic replication cycle of HSV-1, temporally ordered viral gene expression is typically observed, that is, immediate early, early and late gene (Boehmer \& Lehman, 1997; Boehmer \& Nimonkar, 2003). This classification of viral gene is based on the expression timing from the start of the infection. The immediate early gene is expressed within 30 minutes from the infection. The expression of the immediate early gene is introduced by the cooperation between the host transcription factor and VP-16 which is packed in the tegmentum of HSV-1 particle. The protein complex, composed of the host transcription factor and VP-16, binds to the immediate early gene promoter and then activates the immediate early gene expression (Wysocka \& Herr, 2003). Immediate early genes encode the transcription factors. Under the control of the immediate early gene products, other viral genes are expressed (Weir, 2001; Yamamoto et al., 2006). 2 3 hours after infection, the early gene is expressed, delayed from the immediate early gene and proceeding to the late gene. Finally, the late gene expression has started after 8 hours after infection. Both the early and the late gene expression are regulated by the immediate early gene products such as ICP4 (Kim et al., 2002). The difference of the expression timing between the early and late gene is caused by the structural difference of the early and the late gene promoter as shown in Fig.1.

In the early gene promoter, many binding sites to the immediate early gene products are tandemly repeated. On the other hand, the number of repeat binding sites in the late gene promoter is fewer than that in the early gene promoter. The binding affinity of the early gene promoter to the immediate early gene products is higher as compared with the late gene promoter. Therefore the expression of the early gene proceeds to that of the late gene. The mechanism regulating the temporally ordered viral gene expression of HSV-1 is clarified as mentioned above. But the function of this expression pattern is not clear yet. The functional meaning of the expression profile of the HSV-1 gene is theoretically studied (Nakabayashi \& Sasaki, 2009). In this chapter, the function of the 
temporally ordered viral gene expression of HSV-1 is considered from the point of view of the efficiency of the replication of HSV-1. Further, evolution of the temporal expression profile of the viral gene is taken into consideration. From the genome structure of HSV-1, the evolutionary process of HSV-1 is estimated (Umene \& Sakaoka, 1999). Here, the evolution of HSV-1 is evaluated by the efficiency of the replication but not the genome structure. The regulatory system for the efficient replication of virus is developed through the evolutionary process. The HSV-1 genotype whose gene expression is optimally regulated to maximize the virion production is selected through the evolutionary process. It is considered that not only viral replication, but many biological systems, are optimized through the evolutionary process. It is shown that the optimality principle is valid and feasible to understand the mechanism of the biological system (Khanin et al., 2004; Tyurin \& Khanin, 2005, 2006). It is confirmed how viral gene expression is temporally regulated to maximize the virion production by using the evolutionary simulation. The obtained expression pattern obtained from the evolutionary simulation is compared with the observed expression profile of HSV-1 gene.

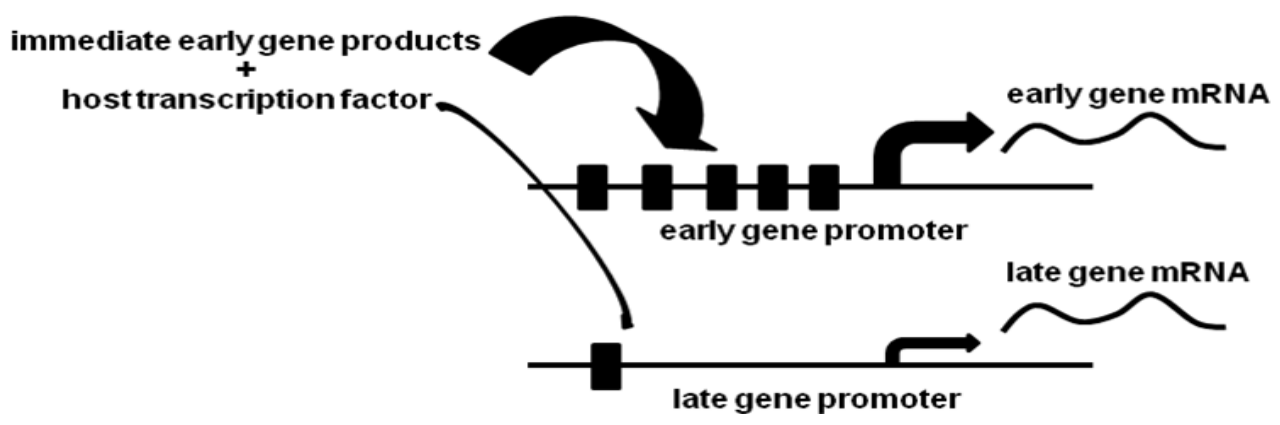

Fig. 1. The structural difference between the early and the late gene promoter. The expression timing of the early and late gene is determined by the structure of their promoters. In the early gene promoter, binding sites for the transcription factor are tandemly repeated. The number of binding sites in the late gene promoter is fewer than that in the early gene promoter.

\section{Function of temporally ordered viral gene expression}

The preceding expression of the early gene is necessary for the efficient replication of HSV-1. Though the classification of viral gene is based on the expression timing after infection, the protein function of viral gene is clearly distinguished between the early and the late gene (Nishiyama, 2004). Early genes encode the enzymes contributing to the DNA replication, while late genes encode the structural proteins of the HSV-1 particle (Cann, 2000). It is theoretically shown that the preceding DNA replication to the assembly of virion is appropriate for the efficient replication of HSV-1. The replication process is schematically shown in Fig. 2. 


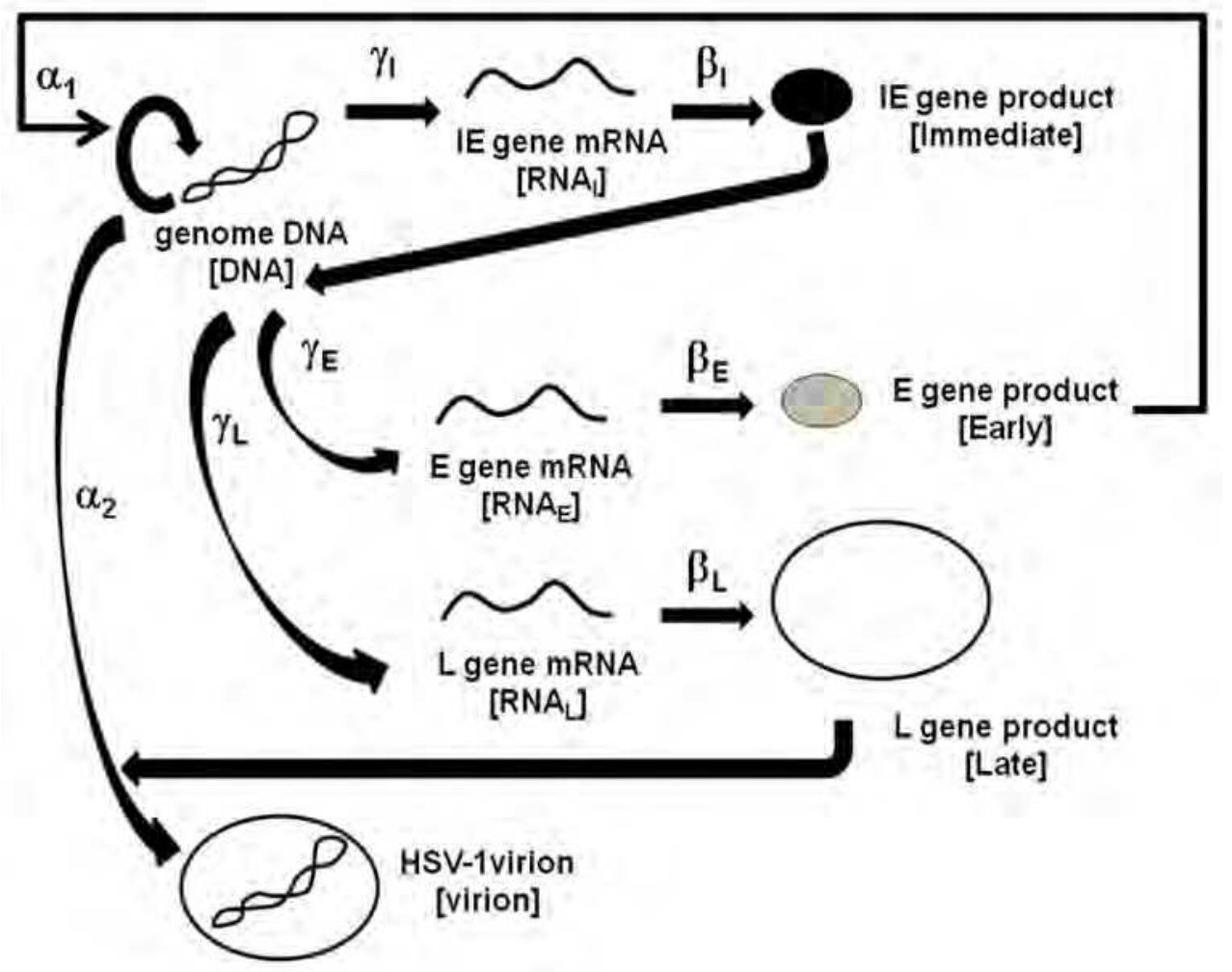

Fig. 2. The intracellular replication cycle of HSV-1. The replication of HSV-1 has started when the genome DNA of HSV-1 invades into the cell. First, the immediate early gene is expressed within $30 \mathrm{~min}$. after infection. Under the control of the immediate early gene, both the early and the late gene are expressed. Early and late gene products contribute to the genome DNA replication and virion assembly, respectively. Finally, the complete virion is newly produced. 
The replication process of HSV-1 is described as a chemical reaction equation as follows:

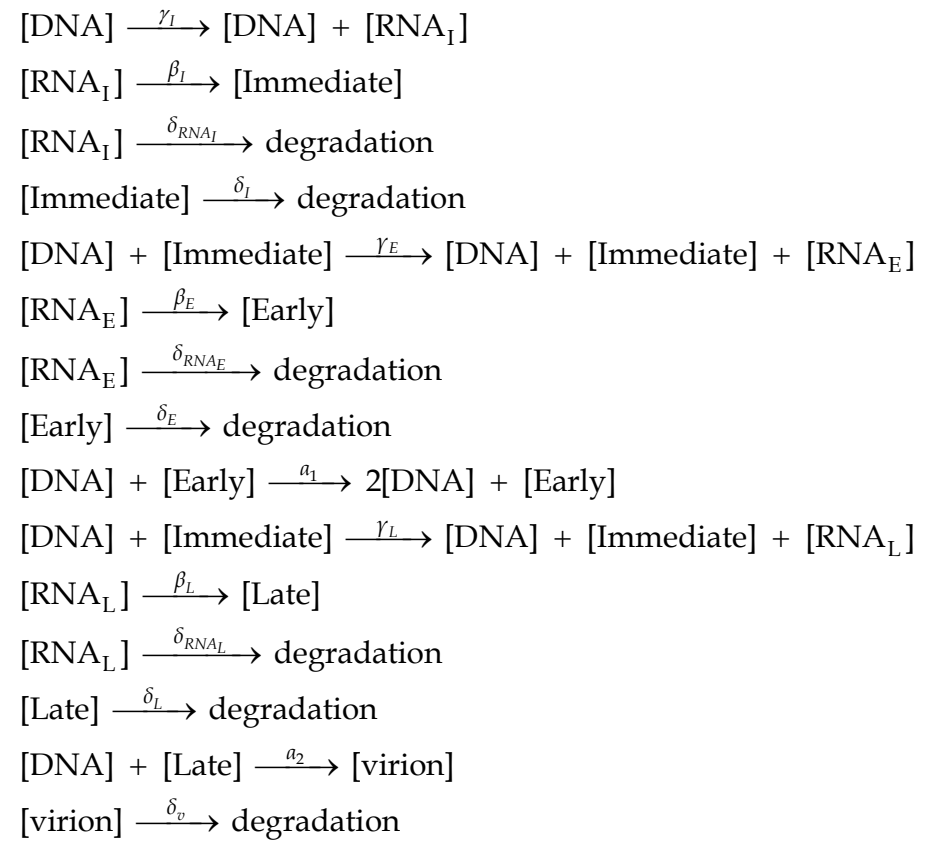

The time change of each viral component is given according to law of mass action.

$$
\begin{aligned}
& \frac{d[\mathrm{DNA}]}{d t}=a_{1}[\mathrm{DNA}][\text { Early }]-a_{2}[\mathrm{DNA}][\text { Late }]-\delta_{\mathrm{DNA}}[\mathrm{DNA}] \\
& \frac{d\left[\mathrm{RNA}_{\mathrm{I}}\right]}{d t}=\gamma_{I}[\mathrm{DNA}]-\delta_{R N A_{I}}\left[\mathrm{RNA}_{\mathrm{I}}\right] \\
& \frac{d[\text { Immediate }]}{d t}=\beta_{I}\left[\mathrm{RNA}_{\mathrm{I}}\right]-\delta_{I}[\text { Immediate }] \\
& \frac{d\left[\mathrm{RNA}_{\mathrm{E}}\right]}{d t}=\gamma_{E}[\mathrm{DNA}][\text { Immediate }]-\delta_{R N A_{E}}\left[\mathrm{RNA}_{\mathrm{E}}\right] \\
& \frac{d[\text { Early }]}{d t}=\beta_{E}\left[\mathrm{RNA}_{\mathrm{E}}\right]-\delta_{E}[\text { Early }] \\
& \frac{d\left[\mathrm{RNA}_{\mathrm{L}}\right]}{d t}=\gamma_{L}[\mathrm{DNA}][\text { Immediate }]-\delta_{R N A_{L}}\left[\mathrm{RNA}_{\mathrm{L}}\right] \\
& \frac{d[\text { Late }]}{d t}=\beta_{L}[\mathrm{RNA} \mathrm{L}]-a_{2}[\mathrm{DNA}][\text { Late }]-\delta_{L}[\text { Late }] \\
& \frac{d[\text { virion }]}{d t}=a_{2}[\mathrm{DNA}][\text { Late }]-\delta_{v}[\text { [virion }]
\end{aligned}
$$


Notations used in the model (1) are summarized in Table1.

\begin{tabular}{cccc}
\hline & Immediate Early & Early & Late \\
\hline mRNA & {$\left[\mathrm{RNA}_{\mathrm{I}}\right]$} & {$\left[\mathrm{RNA} \mathrm{E}_{\mathrm{E}}\right]$} & {$\left[\mathrm{RNA}_{\mathrm{L}}\right]$} \\
Protein & {$[$ Immediate $]$} & {$[$ Early $]$} & {$[$ Late $]$} \\
Transcription rate & $\gamma_{\mathrm{I}}$ & $\gamma_{\mathrm{E}}$ & $\gamma_{\mathrm{L}}$ \\
mRNA degradation rate & $\delta_{R N A_{I}}$ & $\delta_{R N A_{E}}$ & $\delta_{R_{N A_{L}}}$ \\
Translation rate & $\beta_{\mathrm{I}}$ & $\beta_{\mathrm{E}}$ & $\beta_{\mathrm{L}}$ \\
Protein degradation rate & $\delta_{\mathrm{I}}$ & $\delta_{\mathrm{E}}$ & $\delta_{\mathrm{L}}$ \\
\hline
\end{tabular}

Table 1. Notations used in the model (1).

The time course of HSV-1 replication is calculated from this mathematical model (1). The dependence of the intracellular dynamics of virion on the expression rates of the early and the late gene respectively designated by $\gamma_{\mathrm{E}}$ and $\gamma_{\mathrm{L}}$ is investigated. As a result, when the expression ratio $\gamma_{\mathrm{E}} / \gamma_{\mathrm{L}}$ exceeds a certain threshold, HSV-1 virion is continuously reproduced. On the other hand, when the ratio $\gamma_{\mathrm{E}} / \gamma_{\mathrm{L}}$ is smaller than a certain threshold level, HSV-1 replication is arrested. To understand this switching mechanism of the HSV-1 replication, model (1) is simplified for the theoretical analysis.

Model (1) is simplified under a certain constraints as follows:

$$
\begin{aligned}
& \frac{d[\mathrm{DNA}]}{d t}=a_{1}[\mathrm{DNA}][\text { Early }]-a_{2}[\mathrm{DNA}][\text { Late }] \\
& \frac{d[\text { Immediate }]}{d t}=\frac{\beta_{I} \gamma_{I}}{\delta_{R N A_{I}}}[\mathrm{DNA}] \\
& \frac{d[\text { Early }]}{d t}=\frac{\beta_{E} \gamma_{E}}{\delta_{R N A_{E}}}[\mathrm{DNA}][\text { Immediate }] \\
& \frac{d[\text { Late }]}{d t}=\frac{\beta_{L} \gamma_{L}}{\delta_{R N A_{L}}}[\mathrm{DNA}][\text { Immediate }]-a_{2}[\mathrm{DNA}][\text { Late }] \\
& \frac{d[\text { virion }]}{d t}=a_{2}[\mathrm{DNA}][\text { Late }]
\end{aligned}
$$

The diagram of the simplified model (2) is shown in Fig. 3.

Time dependent solutions of [DNA], [Early] and [Late] are obtained as a function of [Immediate] as follows:

$D=D_{0}+\frac{\xi_{L}}{a_{2}}[$ Immediate $]-\frac{\xi_{L}}{2 \xi_{I}}[\text { Immediate }]^{2}+\frac{a_{1} \xi_{E}}{6 \xi_{I}^{2}}[\text { Immediate }]^{3}+\frac{\xi_{I} \xi_{L}}{a_{2}{ }^{2}}\left(-1+\mathrm{e}^{-\frac{a_{2}}{\xi_{I}}[\text { Immediate }]}\right)$

$[$ Early $]=\frac{\xi_{E}}{2 \xi_{I}}[\text { Immediate }]^{2}$

$[$ Late $]=\frac{\xi_{L}}{\left(a_{2}^{2} \xi_{I}\right)}\left(-1+\mathrm{e}^{-\frac{a_{2}}{\xi_{I}}[\text { Immediate }]}\right)$ 
Here, $\xi_{I}=\frac{\gamma_{I} \beta_{I}}{\delta_{R N A_{I}}}, \xi_{E}=\frac{\gamma_{E} \beta_{E}}{\delta_{R N A_{E}}}, \xi_{L}=\frac{\gamma_{L} \beta_{L}}{\delta_{R N A_{L}}}, . D_{0}$ is an initial condition for [DNA]. To investigate the trajectory of [DNA] as a function of [Immediate], the threshold for the continuous replication of HSV-1 without an arrest is analytically obtained as $\gamma_{E} / \gamma_{L}>\alpha_{1} / \alpha_{2}$ from the simplified model (2) and (3). Here $\alpha_{1}$ and $\alpha_{2}$ indicate the reaction rate constant of genome DNA replication and the virion assembly, respectively. Therefore $\gamma_{E} \alpha_{1}$ and $\gamma_{L} \alpha_{2}$ indicate the net genome DNA replication and virion assembly, respectively. This continuous replication of HSV-1 is caused by the effect of the positive feedback in the replication cycle. When the replication of genome DNA exceeds the virion assembly, the viral gene expression is further increased from the replicated viral DNA. Inversely, when the virion assembly exceeds the genome DNA replication, DNA of HSV-1 is consumed by the virion assembly. When all of the HSV-1 genome is consumed, HSV-1 replication is arrested because the template of the replication is absent. This result indicates that the temporally ordered viral gene expression, preceding expression of the early gene to the late gene, is necessary for the efficient replication of HSV-1 without an arrest.

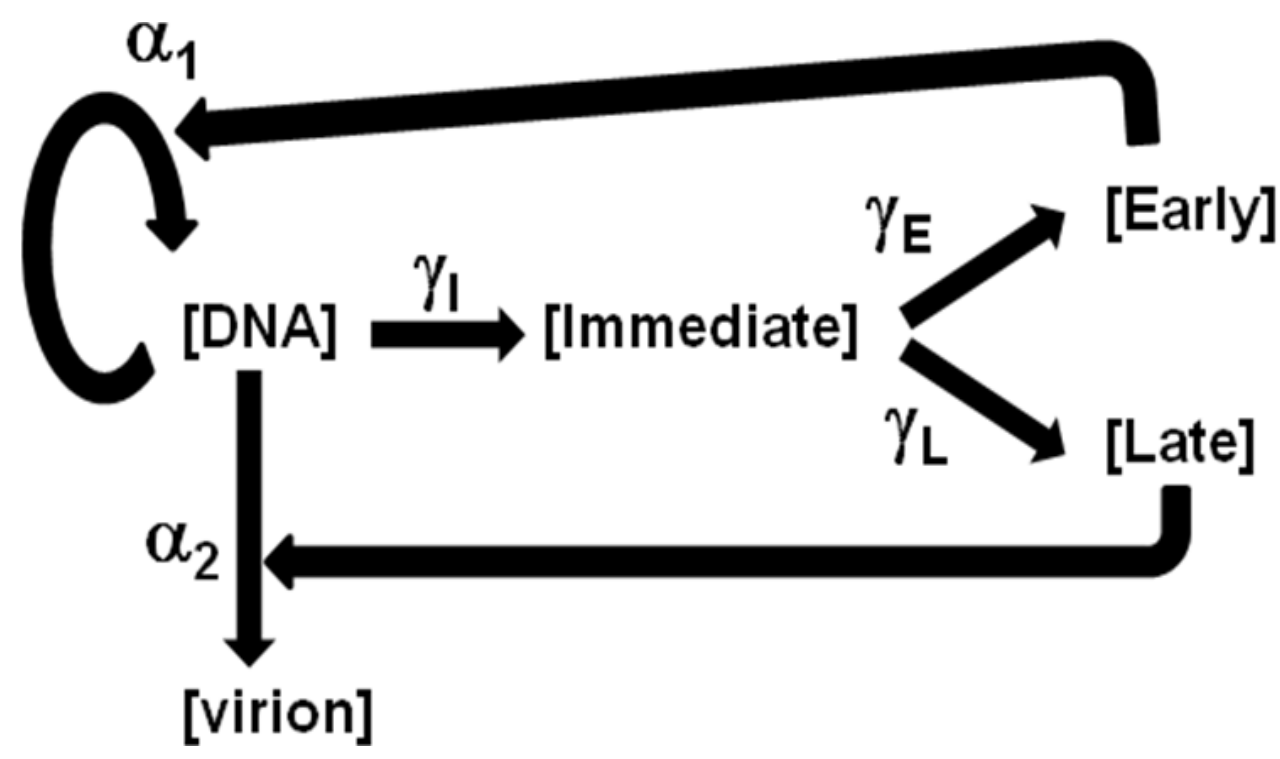

Fig. 3. The diagram of the simplified model (2). 


\section{Evolutionary process of HSV-1 gene expression}

In this section, the evolution of the regulatory mechanism of HSV-1 gene expression is considered. The temporal profile of HSV-1 gene expression is determined by the structure of the promoter region on the HSV-1 genome. The structure of the HSV-1 promoter is changed by the mutation. For example, binding site is newly produced or lost by the point mutation in the promoter region. In the previous section, it is shown that the replication of HSV-1 is critically affected by the expression pattern of the viral gene. If the expression rate of the early gene is affected by the mutation in the promoter region of the early gene, replication dynamics of this mutant is changed as compared with that of the wild type. It is considered that the mutant with large expression rate of early gene becomes advantageous because of the continuous and efficient replication. It is considered that the frequency of the mutant with large expression rate of the early gene increases through the evolutionary process because of the improvement of the efficiency of the replication. It is hypothesized that the temporally ordered expression pattern of viral genes autonomously evolves through such an evolutionary process to maximize the efficiency of the replication of HSV-1. This hypothesis is confirmed by the evolutionary simulation.

\subsection{Evolutionary simulation of the viral gene expression}

Here, the procedure of the evolutionary simulation is briefly explained. Many genotypes of HSV-1 with various expression rates of the early and late genes are generated by drawing the random number. The production of virion of genotype $j$ until a certain waiting time for the virion release designated by $v(j)(\tau)$ is calculated according to the model (1). The frequency of each genotype is determined by the relative virion production designated by $\frac{v_{j}(\tau)}{\sum_{i=1}^{N} v_{i}(\tau)}$. This process means that the frequency of HSV-1 genotype with gene expression rate increasing the virion production increases its frequency. Mutation is reproduced by adding the random number to the expression rate $\gamma_{\mathrm{E}}{ }^{(j)}$ and $\gamma_{\mathrm{L}}(\mathrm{j})$. These processes are iterated over and over. After sufficient iterations, HSV-1 genotype with optimum gene expression rate maximizing the virion production is selected. The procedure of the evolutionary simulation is summarized in Fig. 4.

The initial condition of viral gene expression is set that the expression rate of the early gene is equal to that of the late gene. It is shown by the evolutionary simulation that HSV-1 genotype with large $\gamma_{E}$ and small $\gamma_{L}$ is selected through the evolutionary process. The frequency of HSV-1 genotype with large $\gamma_{E}$ and small $\gamma_{L}$ increases. The mean values of $\gamma_{E}$ and $\gamma_{\mathrm{L}}$ increase and decrease, respectively. This result indicates that the temporally ordered gene expression of HSV-1 autonomously evolves to maximize the replication.

This result indicates that the preceding expression of the early gene to that of the late gene autonomously evolves from the initial condition when the expression rate of the early gene is equal to that of the late gene to maximize the efficiency of the virion production. If the new binding site to the transcription factor is newly created by the mutation in the early gene promoter, the mutant with large expression rate of the early gene becomes advantageous and increases its frequency. As a result, tandemly repeated binding sites observed in the early gene promoter are created. Inversely, a new binding site in the late gene prevents the efficient replication of HSV-1, because genome DNA of HSV-1 is consumed by the excessively expressed late gene product. HSV-1 replication stops because 
of the absence of the template of the replication. The binding site in the late gene cannot increase. The structural difference between the early gene promoter and the late gene promoter is reasonable from the view of the optimization of HSV-1 replication.

1. Generate HSV-1 genotype

$$
p_{j}=\left\{\gamma_{E}^{(j)}, \gamma_{L}^{(j)}\right\} \quad(j=1,2, \cdots, N)
$$

2. Calculate the virion at time $\tau$

$$
v_{j}(\tau)=f\left(\tau, p_{j}\right)
$$

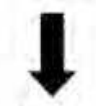

3. Estimate the frequency of HSV-1 genotype

$$
\begin{gathered}
\operatorname{Pr}(j)=v^{(j)}(\tau) / \sum_{i=1}^{N} v^{(i)}(\tau) \\
\downarrow
\end{gathered}
$$

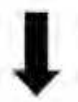

4. Add the random number to the expression rate $\gamma_{E}^{(j)}$ and $\gamma_{L}{ }^{(j)}$

$$
\begin{aligned}
& p_{j}^{\prime}=\left\{\gamma_{E}^{(j)}+\varpi, \gamma_{L}^{(j)}+\pi\right\} \\
& \omega \propto \operatorname{Nom}(0, \sigma)
\end{aligned}
$$

Fig. 4. The procedure of the evolutionary simulation. 
But the genotype of HSV-1 with large $\gamma_{\mathrm{E}}$ and or small $\gamma_{\mathrm{L}}$ is not always advantageous. There is a condition for the evolution of the temporally ordered HSV-1 gene expression. It is also shown by the evolutionary simulation that the long waiting time for the virion release is necessary to evolve the preceding expression of the early gene to that of the late gene. Waiting time designated by $\tau$ is the period when HSV-1 replicates its copy in the infected cell until the newly produced virion is released from the infected cell. When waiting time for the virion release is small, HSV-1 genotype with small $\gamma_{\mathrm{E}}$ and large $\gamma_{\mathrm{L}}$ increases its frequency as shown in Fig. 6.

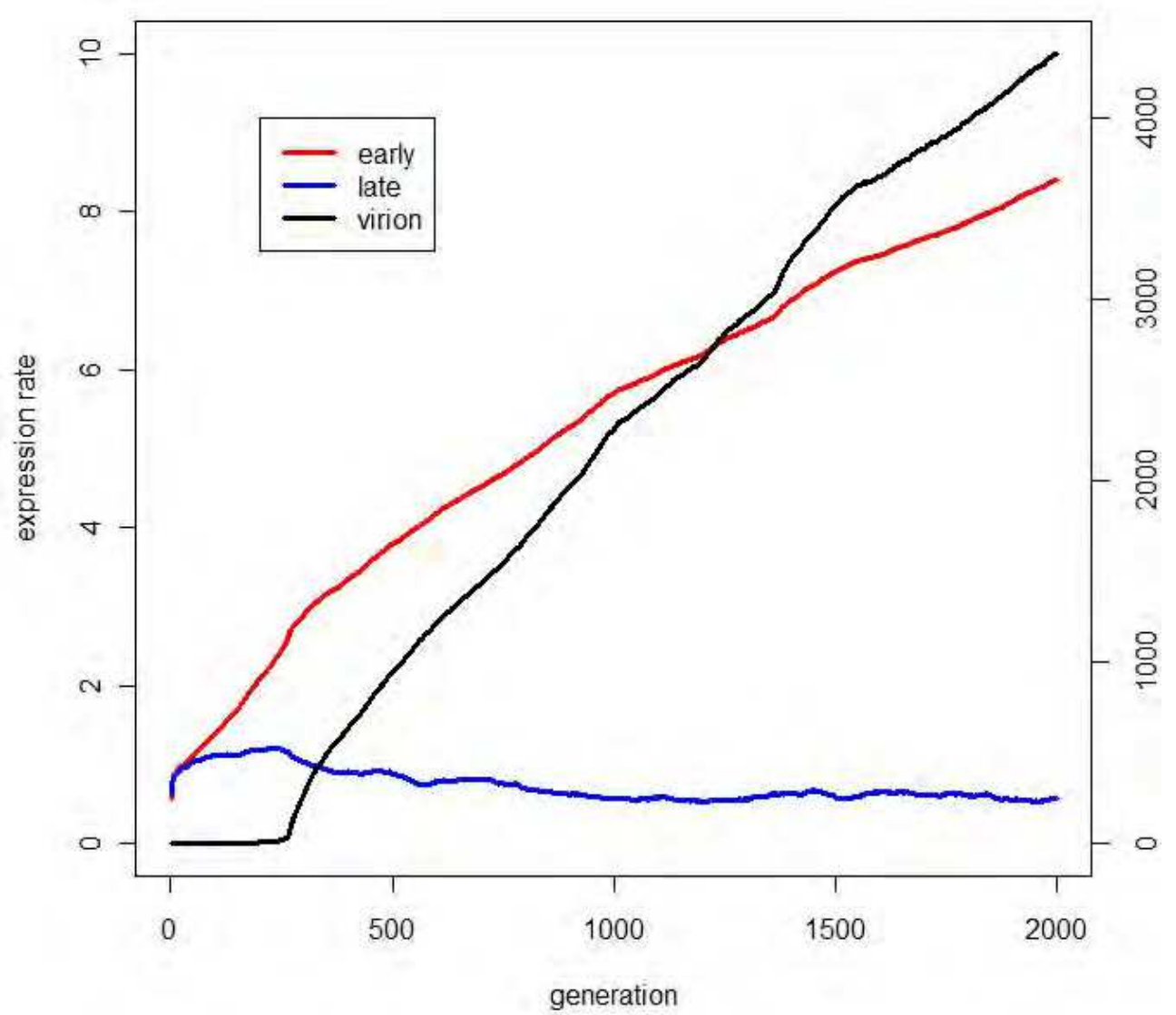

Fig. 5. A sample path of the evolutionary simulation. The mean expression rate of the early (red), late (blue) and mean value of virion (black) of 1000 HSV-1 genotypes are plotted. The initial expression rate of the early gene is equal to that of the late gene. The HSV-1 genotype with large $\gamma_{E}$ increases its frequency as generation proceeds. The virion production rapidly increases when the expression ratio of the early gene to the late gene is larger than a certain threshold level. 


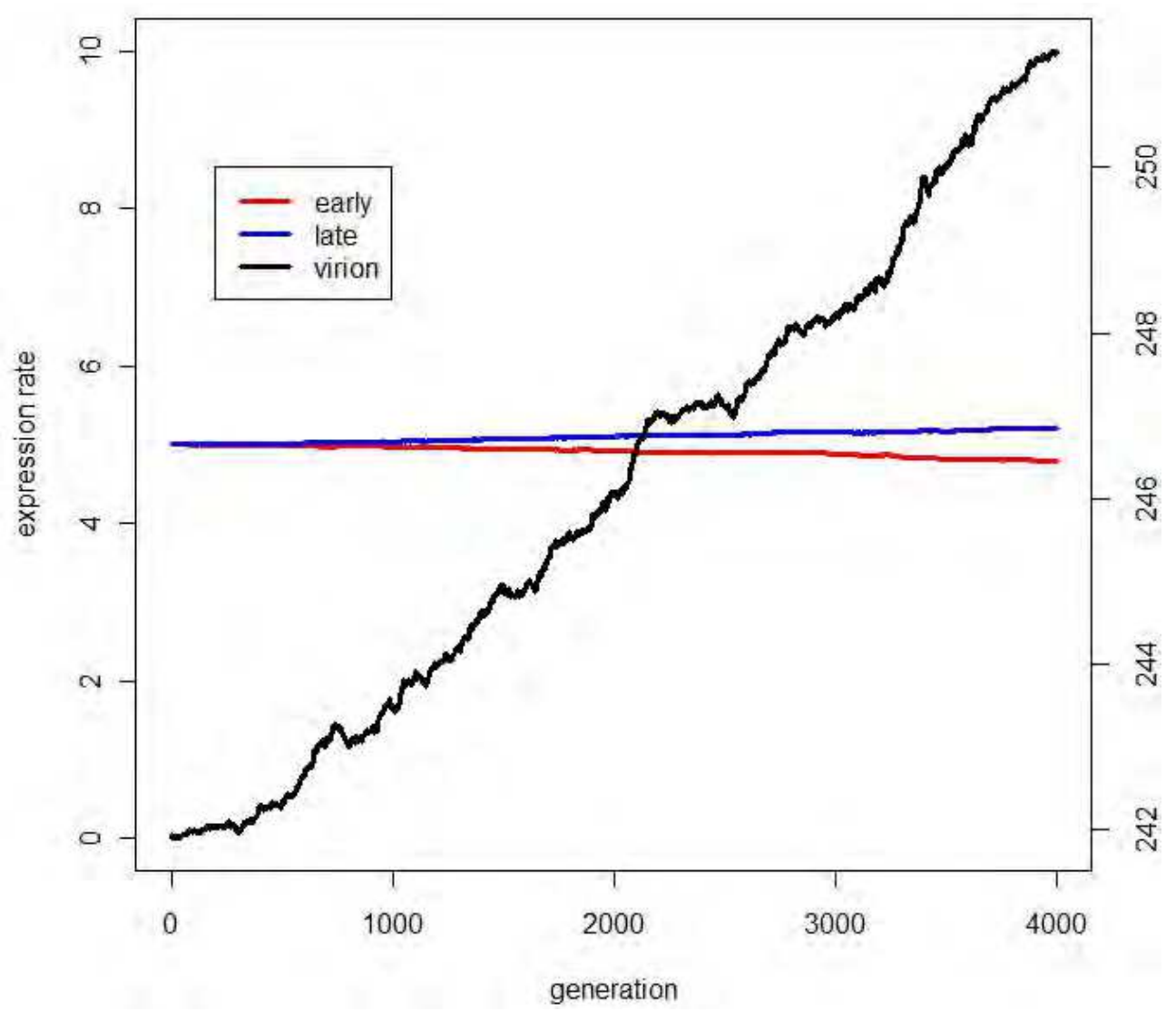

Fig. 6. A sample path of the evolutionary simulation with small waiting time $\tau$. HSV-1 genotype with small $\gamma_{\mathrm{E}}$ (red) and large $\gamma_{\mathrm{L}}$ (blue) increases its frequency as generation proceeds. The virion production (black) slightly increases. Amount of virion remains at a small level as compared with the case when waiting time for the virion release is large.

The virion production of HSV-1 genotype with large $\gamma_{\mathrm{E}}$ and small $\gamma_{\mathrm{L}}$ is delayed in the initial phase of the replication as compared with HSV-1 genotype with small $\gamma_{\mathrm{E}}$ and large $\gamma_{\mathrm{L}}$. As a result, when waiting time for the virion release from the infected cell is small, HSV-1 genotype with small $\gamma_{\mathrm{E}}$ and large $\gamma_{\mathrm{L}}$ becomes advantageous in spite of the fact that the replication of the HSV-1 genotype with small $\gamma_{\mathrm{E}}$ and large $\gamma_{\mathrm{L}}$ is arrested after sufficiently long time has passed after infection. Preceding expression of the early gene to that of the late gene cannot autonomously evolve. This result indicates that there is a trade-off between the initial speed and the final amount of virion production. When the expression of early gene becomes large, virion is continuously produced by the positive feedback in the replication cycle. But it takes much time to produce the virion. Inversely, when the late gene expression is large, virion is reproduced faster. But the replication cycle stops after sufficiently long time has passed because the positive feedback of the replication cannot function. To compare the virion production indicated by right-hand side axis in Fig. 5 and 6, the virion 
production remains small when $\tau$ is small. From the results of the evolutionary simulations, it is suggested that HSV-1 develops the efficient replication system with preceding expression of the early gene to that of the late gene under the condition that the waiting time for the virion release from the infected cell is large.

\section{Conclusion}

The function and the evolution of temporally ordered viral gene expression is investigated from the point of view of the efficiency of the replication. The preceding expression of the early gene to that of the late gene is advantageous for the continuous replication of HSV-1 without an arrest. Continuous replication of HSV-1 is caused by the effect of the positive feedback in the replication cycle. When the expression ratio $\gamma_{\mathrm{E}} / \gamma_{\mathrm{L}}$ exceeds a certain threshold level, the positive feedback can function.

The expression timing of the viral genes is determined by the structure of their promoters. It is suggested by the evolutionary simulation that the tandemly repeated binding sites to the transcription factor in the early gene promoter autonomously evolves through the evolutionary process to maximize the virion production. As the promoter activity of the early gene increases, the efficiency of HSV-1 replication is improved. But large expression rate of the early gene is not always advantageous for the replication. The sufficiently long waiting time for the virion release is necessary to increase the frequency of HSV-1 genotype with large expression ratio of the early gene to the late gene. When waiting time for the virion release is small, the HSV-1 genotype with small $\gamma_{\mathrm{E}}$ and large $\gamma_{\mathrm{L}}$ that faster, but restrictedly, replicates its copy becomes advantageous. Preceding expression of the early gene to that of the late gene can evolve when the waiting time for the virion release is sufficiently long.

\section{References}

Boehmer, P. E.; \& Lehman, I. R. (1997). Herpes simplex virus DNA replication. Annual Review of Biochemistry 66, pp347-384.

Boehmer, P. E.; \& Nimonkar, A. V. (2003). Herpes virus replication. IUBMB Life 55 (1), pp1322.

Cann, A. J. (2000). DNA virus replication Oxford University Press 0199637121 America

Khanin, M. A.; Lobanov, A. N. \& Kaufman, H. (2004). Apoptosis: an optimization approach. Computers in Biology and Medicine 34(5), pp449-459.

Kim, D.B.; Zabierowski, S. \& DeLuca, N. A. (2002). The initiator element in a herpes simplex virus type 1 late-gene promoter enhances activation by ICP4 resulting in abundant late-gene expression. Journal of Virology 76(4), pp1548-1558.

Nishiyama, Y. (2004). Herpes simplex virus gene products: the accessories reflect her lifestyle well. Reviews in medical virology 14(1), pp33-46.

Nakabayashi, J.; \& Sasaki, A. (2009). The function of temporally ordered viral gene expression in the intracellular replication of herpes simplex virus type 1 (HSV-1). Journal of Theoretical Biology 261, pp156-164.

Pande, N. T.; Petroski, M. D. \& Wagner, E. K. (1998). Functional modules important for activated expression of early genes of herpes simplex virus type 1 are clustered upstream of the TATA box. Virology 246, pp145-157. 
Tyurin, K. V. \& Khanin, M. A. (2005). Optimality principle and determination of kinetic constants for biochemical reactions. Mathematical Medicine and Biology 22(1), pp1-14.

Tyurin, K. V. \& Khanin, M. A. (2006). Hemostasis as an optimal system. Mathematical Bioscience 204(2), pp167-184.

Umene, K. \& Sakaoka, H. (1999). Evolution of herpes simplex virus type 1 under herpesviral evolutionary processes. Archives of Virology 144, pp637-656.

Weir, J. P. (2001). Regulation of herpes simplex virus gene expression. Gene 271(2), pp117130.

Wysocka, J.; \& Herr, W. (2003). The herpes simplex virus VP16-induced complex: the makings of a regulatory switch. Trends in Biochemical Science 28 (6), pp294-304.

Yamamoto, S.; Decker, L. A.; Kasai, K.; Chiocca, E. A.; \& Saeki, Y. (2006). Imaging immediate-early and strict late promoter activity during oncolytic herpes simplex virus type 1 infection and replication in tumors. Gene Therapy 13(24), pp1731-1736. 


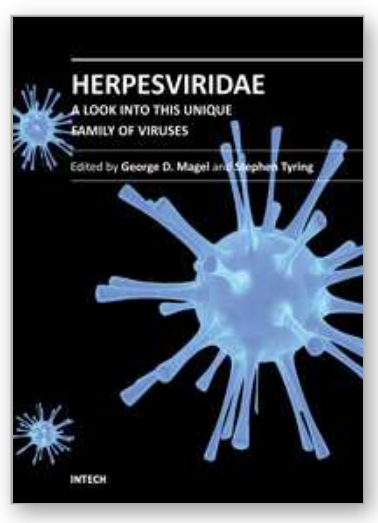

\author{
Herpesviridae - A Look Into This Unique Family of Viruses \\ Edited by Dr. George Dimitri Magel
}

ISBN 978-953-51-0186-4

Hard cover, 320 pages

Publisher InTech

Published online 07, March, 2012

Published in print edition March, 2012

In order to fully understand the nature of viruses, it is important to look at them from both, their basic science and clinical, standpoints. Our goal with this book was to dissect Herpesviridae into its biological properties and clinical significance in order to provide a logical, as well as practical, approach to understanding and treating the various conditions caused by this unique family of viruses. In addition to their up-to-date and extensive text, each chapter is laced with a variety of diagrams, tables, charts, and images, aimed at helping us achieve our goal. We hope that this book will serve as a reference tool for clinicians of various specialties worldwide.

\title{
How to reference
}

In order to correctly reference this scholarly work, feel free to copy and paste the following:

Jun Nakabayashi (2012). Optimal Gene Expression for Efficient Replication of Herpes Simplex Virus Type 1 (HSV-1), Herpesviridae - A Look Into This Unique Family of Viruses, Dr. George Dimitri Magel (Ed.), ISBN: 978-953-51-0186-4, InTech, Available from: http://www.intechopen.com/books/herpesviridae-a-look-into-thisunique-family-of-viruses/optimal-gene-expression-for-efficient-replication-of-herpes-simplex-virus-type-1-hsv1 -

\section{INTECH}

open science | open minds

\section{InTech Europe}

University Campus STeP Ri

Slavka Krautzeka 83/A

51000 Rijeka, Croatia

Phone: +385 (51) 770447

Fax: +385 (51) 686166

www.intechopen.com

\section{InTech China}

Unit 405, Office Block, Hotel Equatorial Shanghai

No.65, Yan An Road (West), Shanghai, 200040, China

中国上海市延安西路65号上海国际贵都大饭店办公楼 405 单元

Phone: +86-21-62489820

Fax: $+86-21-62489821$ 
(C) 2012 The Author(s). Licensee IntechOpen. This is an open access article distributed under the terms of the Creative Commons Attribution 3.0 License, which permits unrestricted use, distribution, and reproduction in any medium, provided the original work is properly cited. 